\title{
Risk in Public Contracts - The Treatment and the Regulation
}

A significant regulatory trend which has emerged as a result of the strategic role of the private sector and its long-term engagement in delivering infrastructure and public services reflects on the legal treatment of risk distribution between the public and private sectors within Public-Private Partnerships and in particular, the allocation and pricing of construction or project risk, which is related to design problems, building cost overruns, and project delays; financial risk, which is related to variability in interest rates, exchange rates, and other factors affecting financing costs; performance risk, which is related to the availability of an asset and the continuity and quality of the relevant service provision; demand risk, which is related to the on-going need for the relevant public services; and residual value risk, which is related to the future market price of an asset. Risk transfer from the public sector to the private sector has a significant influence on whether a Public-Private Partnership is a more efficient and cost-effective alternative to public investment and publicly funded provision of services.

The cost of capital needed to finance a Public-Private Partnership should depend on the characteristics of project related risks and not on the source of finance. However, the source of finance can influence project risk depending on the maturity and sophistication of the risk bearing markets. On the one hand, within advanced risk bearing markets, it is irrelevant whether project risk is borne by the public sector or the private sector. On the other hand, when risk bearing markets are less developed, project risk depends on how widely that risk is spread. This outcome might contravene the assumption that private sector borrowing generally costs more than government borrowing. However, this mainly reflects differences in default risk. The public sector's power to tax reduces the likelihood that it will default on its debt, and the private sector is therefore prepared to lend to the public sector at close to the risk-free interest rate to finance risky projects. The crucial issue is whether Public-Private Partnerships result in efficiency gains that offset higher private sector borrowing costs. Risk transfer from the public sector to the private sector has a significant influence on whether a Public-Private Partnership is a more efficient and cost-effective alternative to public investment and publicly funded provision of services. The public sector and the private sector typically adopt different approaches to pricing market risk. The public sector tends to use the social time preference rate (STPR) or some other riskfree rate to discount future cash flows when appraising projects. The private sector will include a risk premium in the discount rate it applies to future project earnings, where under the widely used capital asset pricing model (CAPM), the expected rate of return on an asset is defined as the risk-free rate of return plus a risk premium, the latter being the product of the market risk premium and a coefficient which measures the variance between the returns on that asset and market returns.

A number of criteria have been devised to assess the degree of risk treatment in PublicPrivate Partnerships and these criteria involve asset ownership as an essential feature. The extent of risk transfer between the parties and the quantum for such transfer can be assessed by reference to the nature of contractual relations in a Public-Private Partnership. A 
distinction is made between separable PPPs, where asset ownership and delivery of public service elements are different features, and non-separable PPPS, where asset ownership fuses with public service delivery.

Optimal risk management is the prime advantage to the state which emerges from involving private actors through a partnership format in the delivery of public services. This axiom underlines the principle of public accountability for the modern state in a number of ways. The private actor partner often commits its own capital resources for the funding and the delivery of public services. It is not therefore a mere contractor; it is a stakeholder which has a vested interest in the effective and efficient delivery of the relevant public services in order to attain its returns and recoup its investment. This attribute results in an increased certainty of outcomes, both in terms of on-time delivery (the private actor is strongly motivated to complete the project as early as possible and to control its costs and so that the payment streams can commence) and in terms of within-budget delivery (the payment scheduled is fixed before construction commences, protecting the state from exposure to cost overruns). As a result, by transferring the risk of the funding required for the delivery of public services to private actors, the latter become an essential component of the state's functions, thus revealing a conceptual and strategic convergence between public and private sectors. Private actors in Public-Private Partnerships are often financially incentivised to offer value-for-money solutions in the delivery of public services through continuous quality improvement, innovation, management efficiency and effectiveness. As such, behavioural elements which traditionally underpin private sector entrepreneurship are harnessed by the state to enhance the quality of public services through a transfer of operational risk to private actors.

\section{Managing Risk}

A PPP is legal arrangement which codifies vertically or laterally integrated allocations of rights within a consortium. A PPP essentially tries to defend legally the boundaries of a consortium, the organisation of activities within a consortium, and reflect on the design of relationships between public and private actors, in terms of their respective rights and obligations (eg funding, purchase, provision of services, and provision of guarantees). At the same time, the security of property rights is almost synonymous with the commitment and capacity of government bodies to enforce them, as well as with the general normative legitimacy of the established law. What is essential is that investors' rights are clearly defined and adequately protected; therefore compensation standards and limits to expropriation must be clearly stated and enforced. PPP therefore seeks to govern how the risks taken by each party may be efficiently managed, away from long-running legal conflicts over the security of property rights as much as possible.

PPP arrangements are likely to result in divisions of property rights, or frequent contestation of property rights, with large rewards for displacing other claimants. Similarly, the whole process of procurement a PPP generally presents unusual regulatory, liability, or regulatory issues. Indeed, this type of public service implies several tasks that can be split between public and private authorities and that may differ depending on the kind of public services concerned. In addition, the management of public services is quite complex due to the diversity of such tasks, all of which require the coordination of different institutions and organizations. Even though the significance of government enforcement capacity by emphasizing that fear of legal sanctions is only one of the motives that can inspire behaviour conforming with law, issues regarding how situational incentives (potential costs and benefits of violating the contractual obligations in some specific instance) also tend 
to contribute to law-compatible action. Essentially, the relevant decision is whether to contest property rights claimed by someone else, either via litigation or simply by taking actions that negate these claimed rights, must, in actuality, be weighed against costs and benefits.

Of particular interest are the various problems related to the sharing of risks between different partners in a PPP project, recognizing that all approaches to procuring, financing and operating infrastructure assets all entail risks. While there are risks with PPPs that public officials need to be aware of, it is important to recognize that these risks are manageable and that public officials can mitigate these risks if they take prudent and reasonable steps to ensure that they are creating well balanced PPP programs, performing necessary due diligence before committing to projects, and negotiating well structured concession agreements. In addition, the risks associated with PPPs need to be evaluated in the context of the failings of traditional approaches to project funding and delivery. This includes both the risk sharing between the private and the public sector and the distribution of risk among the involved private firms, such as the members of a consortium but also their relations to banks and similar institutions. Particularly, in transferring responsibility and risk for multiple project elements to the private partner, the procuring government authority shifts certain risks to the private partner and focuses on getting the optimum project for the optimum price instead of detailed project specifications as change is certainly inevitable. The impact of risks to project objectives in completing a PPP project is indeed significant, and these risks arise from multiple sources, due mainly to the complexity and nature of the disciplines, public agencies and stakeholders involved. Both the private and public sectors need to have a better understanding of these risks in order to achieve an equitable risk allocation and enable the project to generate better outcomes. In fact, a fair and reasonable allocation of various risks is vital to PPP success. If risks are inequitably or wrongly allocated beyond the capacity of the parties concerned, PPP projects would fail.

Under traditional public procurement, the government bears all or most of the risks. Under PPP, a major advantage is that as many risks as appropriate are moved to the private sector, which also then receives the rewards for its investment and risk. Accordingly, a contract of this nature is purported to allow the private sector to pursue its goal of realizing a profit while at the same time guarding the interest of the general public as users of the infrastructure facility. The partnership between government and the private sector is therefore governed by the principle of mutualism. Risks and contracts are central to these arrangements. In fact, the PPP paradigm is founded, rather significantly, upon the concept of risk allocation through contracts. Risks, for example, can be looked at from the perspective of the different parties concerned: the sponsors, the lenders, the government, and the users/clients of the project. Risks can also be grouped into categories according to type: commercial risk, that is, risks related to the sector or business activity being contemplated (eg, cargo handling in a port, investment in an airport or a ferry terminal); risks specific to a country (including political, economic, and financial risks); or risks of a general nature such as force majeure; Risks can also be differentiated according to when they arise in the project cycle eg development phase risk, construction phase risk, and operation phase risk. PPP risks are both generic and project specific.

At the same time, to ensure, therefore, the success of a project, there needs be optimal sharing of risk between the public and private sector, with each partner retaining the risk which they are best placed to manage. The transfer of risk through the contractual framework often is the basis for the decision to deliver public services by a PPP arrangement as it basically sets forth the rights and obligations of the government and private investors, in general, in connection with the implementation of the PPP project. In this sense, a PPP 
contract becomes the mechanism to transfer the rights and obligations of the investors to a PPP company (SPV). On the foundation of this agreement, or an ancillary project contract, the PPP and the government agree on a new contract which restates the rights and obligations of the PPP company in the implementation of the project. The law should also include the provisions of a liberalized the regulatory framework for pricing using market-based principles in rate setting and adjustments to allow equity investors a competitive rate of return. This argument, however, does not presume the existence of complete contracts to cover any and every contingency or eventuality. The fact of the matter is that design and construction contracts are often problematic and unbundling construction from service provision appeared more appropriate.

At the core of successful risk management strategies, accordingly, the contract formation process requires a highly efficient integrated approach to risk sharing with proven execution and control processes. This approach will tend allow the parties involved to achieve negotiated, contextually-specific appropriate recognition of their stakes as part of the procurement process. Importantly, the parties can indeed mitigate risks within the framework of a PPP by taking prudent and reasonable steps to ensure that they are creating well-balanced PPP programs, where the negotiations involve structuring the relational context in which the post-procurement property rights would operate. In the end, the most successful solutions to legislative requirements are those that give PPP project participants the flexibility to develop the optimal project delivery structure for a particular project. Indeed, as a result of creation of innovative contracting program, many PPPs have been permitted to use many experimental contracting approaches on risk sharing. Contractual requirements and market forces thus hold a private contractor to a greater level of accountability for the operation and maintenance of a facility than would otherwise be required of public authorities. The successful implementation of these approaches may ultimately encourage government authorities to determine that these approaches have become operational and are no longer experimental techniques.

The wide-ranging array of uncertainties implicated in the project requires government agencies and private organisations to focus cooperatively on the long term legal contract preparation, as well as establish actual effective risk sharing mechanism in contract, in order to ensure the successful running of the project. Private operators are bound by contractual requirements and market incentives to be good stewards of facilities and services for which they have assumed a long-term financial risk. In a PPP, a private entity is authorized to operate facilities through carefully negotiated agreements with the public authority. These agreements specify performance standards with which the operator must comply relating to facility conditions, safety measures, levels of service and maintenance obligations, among other things (these standards can exceed the standards to which other publicly maintained facilities are subject). Failure by the private operator to meet these performance standards can lead to operating control of the facility and the right to collect further revenues reverting from the operator to the public authority. In this vein, there is greater accountability for its operation and maintenance under the concession, which specifies detailed operations and maintenance standards based on industry best practices, than there has usually been under public control when there are weaker formal standards. For a private operator, accountability to the public authority that granted the concession and to the users of the facility is of primary importance because the concession is the operator's source of revenue. To the extent performance lags and revenues suffer (either through a contractual mechanism or through market forces) the operator bears the risk of defaulting on debt service payments, reporting losses to its shareholders and potentially losing the concession. 
PPP projects encounter several risks that often lead to cancellations and/or significant renegotiations even when favorable conditions exist. PPP projects are by nature long-term investments involving complex organizational structures leading to increased risk exposure for all the parties involved. Principal causes for such a low implementation rate are due contract failure to accurately identify and make appropriate allowance for risks being assumed under complex commercial and contractual arrangements. Risk may in effect result from the direct and indirect adverse consequences of outcomes and events that have not been accounted for or that have been ill prepared for, and concerns their effects on individuals, firms or society at large. It can result from many reasons both internally induced and occurring externally with their effects felt internally. The evidence indicates that over the lifespan of these projects the technological, market, organisational, financial and turbulence environment could all change significantly. Thus a high degree of resulting risk and uncertainty surround PPP infrastructure projects and it is critical that adequate identification, assessment, and evaluation of risk factors should be ensured to guarantee maximizing the results of positive events and minimizing the consequences of adverse events.

PPP risk transfer is indeed a form of risk management which has been employed for many years in the industry. It involves the allocation or distribution of the risks inherent to a project between or among contracting parties. If done effectively, risk transfer does not grossly or inequitably allocate all risk to one party, but instead places risk upon parties according to their ability to control and insure against risk. Additionally, effective risk management typically generates positive results on a project by improving project performance, increasing cost effectiveness and creating a good working relationship between contracting parties.

In general, risk allocation management within the context of PPP is established by the contract. The importance of the contract cannot be overemphasized. Today's competitive and complex public procurement requires careful consideration in the formation of the construction contract to ensure that the contract is equitable and the specifications and timetable feasible, and that liability and obligations are clearly defined. Properly prepared contractors, subcontractors, architects, engineers, and developers can avoid anticipated problems, reduce performance disputes and receive returns on the work performed. Ideally, the parties, in their contract, will assign the risks and liabilities to the party best equipped to manage and minimize them. The contracting process provides the vehicle for each party to negotiate, define and limit its rights in accordance with its goals. The risks and responsibilities associated with a specific project must be clearly allocated within the contract. In the end, the contract serves as a framework of the law between the parties and will establish which party has assumed or negated a particular risk in connection with the project.

Every PPP project is a long-term arrangement of transfer of risks which are traditionally borne by the public sector to the private sector for which the latter is financially compensated for the willingness to bear the risks. PPP is an effective approach to enhance project productivity by bringing in management efficiency and creative skills from business practice, and reducing governmental involvement by using private sectors in the provision of public services. A PPP contract apportions the project-associated risks mainly to public and private sector. Best practice suggests an optimal rather than a maximum risk transfer from the public to private sector. A problem may, however, occur if risk is inappropriately transferred, as the government may pay a premium higher than necessary or jeopardize the long term sustainability of a PPP arrangement or is merely gaining the illusion of risk transfer, since it is likely that the risk will be transferred back to the government in the form of higher risks, risk premiums, and project problems. The issue of balancing project risks 
is more exuberated in the context of complex projects where the potential for competition is much more limited than it is in other sectors.

Under the PPP approach, the project associated risks are transferred from the public to the private sector. The central issue to address is who best bears what risk. Efficient risk allocation dictates that risk must rest with the most able party to retain. If the principle is violated, the government may face higher risk premium than necessary or illusion of risk transfer. Additionally, the basic principles of transparency, cost effectiveness and quality soundness must be ensured in all decisions. Understanding, therefore, the process of proper risk allocation will certainly help translate the project risks into effective PPP contracts, depending on the scope of defined tasks and responsibilities, and thus avoid the so-called 'illusion of risk transfer' in the quest for more efficient service provision to the public.

Professor Christopher Bovis FRSA 